\title{
Megan Coder
}

\section{It's not easy being green \\ Or is it?}

$I^{\prime}$ is encouraging to read about the many green movements happening in libraries nationwide. The April 2008 edition of American Libraries highlighted libraries that have gone green recently with either LEED (Leadership in Energy and Environmental Design) certi ed buildings or renovations with reused or recycled materials. However, if an eco-friendly remodel is not in the foreseeable future at your library, there are other environmental initiatives your library can take.

\section{Join the discussion}

Environmental discussions are taking place among libraries in several forms. I had the opportunity to participate in the online course Eco-Librarians: Changing Our Communities One Step at a Time, offered through the University of Wisconsin March 31 April 26, 2008. This online forum consisted of academic and public librarians from all over the United States, and other countries, including the Bahamas. Lively discussions were held on various issues, some of which included the role libraries play in the environmental movement, the green practices many libraries have established, and environmental programming ideas.

Another online discussion that recently took place was through the ACRL OnPoint series. This free online chat through the Web 2.0 instant messaging technology, Meebo, was about Green Libraries and how to be more sustainable institutions. ${ }^{1}$ The best way to nd out about these opportunities is to join the ALA Task Force on the Environment (TFOE) e-mail discussion list. ${ }^{2}$

\section{Recycle}

If your library does not have a recycling pro- gram, establish one. The support of upper management may be needed, but if you can get recycling bins situated throughout the library, it will prove to be a positive implementation for both library patrons and staff.

Once I discovered that the State University of New York (SUNY)-New Paltz had a student recycling coordinator, I contacted this student to see what to do to get a recycling system set up in the Sojourner Truth Library (STL). The process involved many conversations with the facilities operations and meetings with the director and library staff, but after a few months STL was given new recycle bins, and recycling has been going strong ever since.

Investigate companies that could recycle your library s materials. When STL deselected some of the micro $1 \mathrm{~m}$ collection, I found out about a company called Safety-Kleen that was able to take the micro $1 \mathrm{~m}$ and recycle it.

If printing and photocopying is one of your library s busier services, contact those vendors to nd out if they recycle the toner and ink cartridges because these supplies will often need to be replaced.

\section{Reduce and reuse}

Be mindful of the environment when your library holds staff meetings or parties. This year s staff appreciation party at STL was green. Instead of purchasing disposable plates, cups, and atware, librarians brought their own dinnerware and asked staff members to bring their own cups. It was great to see the library

Megan Coder is reference librarian at the State University of New York-New Paltz, e-mail: coderm@newpaltz. edu

() 2008 Megan Coder 
staff working together at the end of the party cleaning dishes and remarkable that we did not generate even one bin of trash.

Collect donated books and hold book sales at your library. This not only will save land 11 space, but will also be pro table for your library. The Friends of the Library at STL hold book sales every semester, and they are always very popular events.

Libraries should not disregard smaller-scale efforts like reusing one-sided print jobs as scrap paper and providing cloth bags instead of plastic at the circulation desk. All these efforts add up and can positively in uence our users.

\section{Partnerships}

Look within your community to nd partnerships and take environmental action together. It never hurts to have the library tied to another organization s name like the local chapter of the Nature Conservancy or a community garden.

I am fortunate to work on a campus where there is an environmental task force (ETF) consisting of students, faculty, staff, and community members. We work together to make the campus as environmentally friendly as possible.
I joined ETF when I rst started working at the library, and it has been a great way to meet other people who are also passionate about environmental issues.

Through ETF, I met the dean of science and engineering department and was able to partner with him to organize an environmental lecture about his research during National Library Week. It was great public relations to have the library partner with ETF because we were seen not only as supporters of access to information but also of the environment.

\section{Start a program}

Make the environment the theme for library programming. Last year, I successfully led and organized a book discussion on Rachel Carson s silent Spring. I created a handout of discussion points for participants and a display of books and information about Carson and the controversy surrounding Silent Spring. This event was well attended with students, faculty, and community members, and the discussion was vibrant and informative.

Libraries are places that can bring communities together. We have the power to

\section{ACRL 2009 Green Pledge}

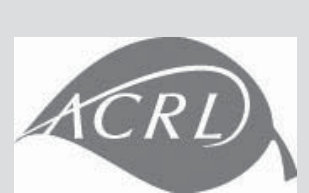

The following pledge is meant to guide your actions during the ACRL 14th National Conference. It is a set of commitments you can easily incorporate into your conference and daily professional activities.

During the ACRL 14th National Conference in Seattle, I will endeavor to ...

- Learn: Educate myself about the environmental impact of conferences.

- Inform: Share information about available green services and programs with colleagues.

- Think: Make a sustainable mindset second nature.

-Act:Put sustainable ideas into practice. Suggested activities: Take public or shared transportation to and from the airport. Walk or use public transportation in Seattle. Consult the ACRL interactive conference map for local and green restaurants and businesses to patronize. Consult the ACRL conference program to learn which vendors provide sustainable services and practices, and visit them in the exhibit hall.

- Reduce: Use digital copies of handouts and presentation materials whenever possible. Turn off lights and unplug personal electronics when I'm not using them in my hotel room. Take shorter showers.

- Reuse: Use my ACRL or other reusable mug for coffee, water and other beverages. Participate in my hotel's towel and linen reuse program if available.

- Recycle:All paper materials that I don't take home from the conference, as well as food and other containers whenever possible.

Look for the check box on the ACRL National Conference registration form, at www.acrl.org/seattle, to indicate that you accept the Green Pledge. 
educate different populations, and the environment should be at the forefront of our outreach efforts.

I am happy to see that being green is making many newspaper and magazine headlines and is a hot topic on many television programs. From what I have observed, it seems as though many libraries are also trying to make a greater impact by instituting practices and services that have less of an impact on the planet. I applaud those efforts and hope libraries continue to be positive in uences to our users, other institutions, and the environment. As Kermit the Frog so eloquently stated, I am green and it 11 do ne, it s beautiful! And I think it s what I want to be.

\section{Notes}

1. ALA Task Force on the Environment email discussion list can be found at www.ala. org/ala/srrt/tfoe/taskforceenvironment.cfm.

2. The ACRL OnPoint green chat transcript can be found at www.ala.org/ala/mgrps/ divs/acrl/proftools/OnPoint/archives/2008 $-05-14 . \mathrm{cfm} \approx$

\section{ANTIOCH}

Ph.D. in Leadership \& Change

This distinctive program is for professionals seeking a degree that offers:

- Quarterly residencies

- Learne

- Integration of theory and practice

- Flexibility of pace to completion

website: www.phd.antioch.edu

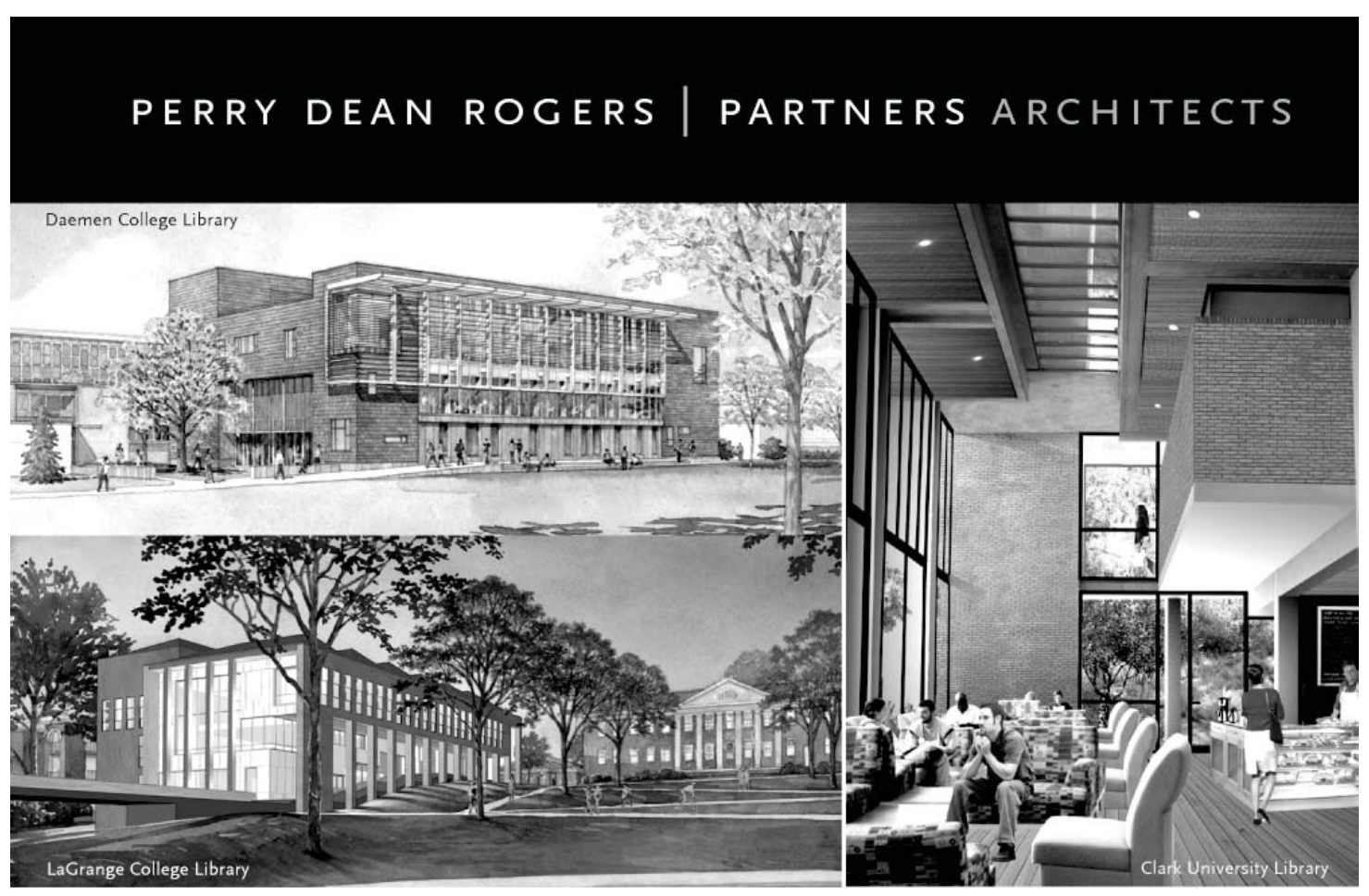

\section{Designers for Libraries \& Academic Institutions}

